\title{
ANALISIS PERBEDAAN KINERJA SOSIAL DENGAN INDEKS ISLAMIC SOCIAL REPORTING (ISR) PADA PERBANKAN SYARIAH YANG ADA DI INDONESIA DAN MALAYSIA']
}

\author{
Aprilia Dwi Widayati \\ Mahasiswa Program Studi Ekonomi Islam-Fakultas Ekonomi dan Bisnis-Universitas Airlangga \\ Email: aprilia.dwi-12@feb.unair.ac.id \\ Raditya Sukmana \\ Departemen Ekonomi Syariah-Fakultas Ekonomi dan Bisnis-Universitas Airlangga \\ Email: raditya-s@feb.unair.ac.id
}

\begin{abstract}
:
The purpose of this research is to examine the difference of Islamic Social Reporting (ISR) disclosure level of islamic banking in Indonesia and Malaysia based on ISR index. The samples were selected by purposive sampling method. The samples that is used in this research is five islamic banks in Indonesia and five islamic banks in Malaysia. This research uses secondary data, that is annual report from 2010-2012. Annual reports were analyzed using content analysis method. Furthermore, the differences of ISR disclosure level were tested using independent sample t-test. The results showed that ISR disclosure level of islamic banking in Indonesia is better than ISR disclosure level of islamic banking in Malaysia. Based on the results of hypothesis testing, found that there are significant differences in the disclosure level between islamic banking in Indonesia and Malaysia.
\end{abstract}

Keywords: Islamic Social Reporting, Islamic Social Reporting Index, Islamic Banking

\section{PENDAHULUAN}

\section{Latar Belakang}

Dengan semakin berkembangnya perekonomian dunia maka tidak dapat dihindari bahwa setiap perusahaan kini dituntut oleh masyarakat agar tidak hanya memikirkan bagaimana meningkatkan laba perusahaan tetapi juga memperdulikan lingkungan dan masyarakat sekitarnya. Selain itu perusahaan juga dituntut untuk mengungkapkan pertanggungjawaban sosial yang telah dilakukannya di dalam laporan tahunan dengan tepat agar dapat memberikan nilai lebih terhadap perusahaan.

Seiring berkembangnya perbankan syariah di kancah internasional dan terkait dengan adanya tuntutan dalam pengungkapan tanggungjawab sosial pada suatu perusahaan, Islamic Social Reporting telah menjadi topik terkini. Islamic Social Reporting merupakan perluasan dari pelaporan sosial yang telah disisipkan nilai-nilai Islam di dalamnya untuk membantu perusahaan islam dalam mengungkapkan tanggungjawabnya pada laporan tahunan.

Pada periode 1990-an, sektor keuangan di Indonesia semakin marak dengan hadirnya lembaga-lembaga keuangan yang beroperasi berdasarkan prinsip-prinsip ajaran islam atau syariah Islam. Meskipun Indonesia merupakan negara dengan penduduk yang mayoritas beragama muslim, tetapi Indonesia bukanlah negara pertama yang menerapkan lembaga keuangan

1] Jurnal ini merupakan bagian dari skripsi dari Aprilia Dwi Widayati, NIM: 041211431166 , yang diuji pada tanggal 8 juni 2016 
Widayati, et al/Jurnal Ekonomi Syariah Teori dan Terapan Vol. 4 No. 1 Januari 2017: 62-72; ANALISIS PERBEDAAN KINERJA SOSIAL DENGAN INDEKS ISLAMIC SOCIAL REPORTING (ISR) PADA PERBANKAN SYARIAH YANG ADA DI INDONESIA DAN MALAYSIA

berlandaskan prinsip syariah 45,4\%. Sedangkan negara Malaysia telah terlebih dahulu mendirikan bank syariah jauh sebelum Indonesia, atau dengan kata lain negara Malaysia merupakan pelopor perbankan syariah di Asia Tenggara dengan pertumbuhan aset perbankan syariah yang sangat tinggi di dunia.

Indeks ISR merupakan suatu tolak ukur pelaksanaan tanggungjawab sosial perbankan syariah yang berisi kompilasi item-item standar yang ditetapkan oleh AAOIFI (Accounting and Auditing Organization for Islamic Financial Institutions) yang seharusnya diungkapkan oleh suatu entitas Islam.

Haniffa (2002) berpendapat bahwa pelaporan tanggung jawab sosial perusahaan pada sistem konvensional hanya berfokus pada aspek material dan moral. la menambahkan bahwa seharusnya aspek spiritual juga dijadikan sebagai fokus utama dalam pelaporan tanggung jawab sosial perusahaan karena para pembuat keputusan Muslim memiliki ekspektasi agar perusahaan mengungkapkan informasi-informasi terbaru secara sukarela guna membantu dalam pemenuhan kebutuhan spiritual mereka. Oleh karena itu, ia memandang bahwa perlu adanya kerangka khusus untuk pelaporan pertanggungjawaban sosial yang sesuai dengan prinsip Islam. Kerangka tersebut tidak hanya berguna bagi para pembuat keputusan Muslim, tetapi juga berguna bagi perusahaan Islam dalam memenuhi pertanggungjawabannya terhadap Allah SWT dan masyarakat. Kerangka ini dikenal dengan sebutan Islamic Social Reporting (ISR).

Pelaporan sosial yang sesuai dengan prinsip Islam akan semakin nampak pada pelaporan sosial bank Islam. Bank Islam yang operasi idealnya berdasarkan dengan prinsip hukum Islam dan sebagai salah satu bentuk bisnis Islam dengan jelas pelaporan sosialnya akan berdasarkan prinsip Islam (Haniffa, 2002).

Perumusan Masalah

Apakah terdapat perbedaan pengungkapan Islamic Social Reporting (ISR) pada perbankan syariah yang ada di Indonesia dan Malaysia ditinjau dari periode 2012-2014?

Tujuan Penelitian

Untuk menganalisis perbedaan pengungkapan Islamic Sosial Reporting pada perbankan syariah yang ada di Indonesia dan Malaysia dari periode 2012-2014.

\section{LANDASAN PUSTAKA}

Pengungkapan secara sederhana dapat diartikan sebagai pengelvaran informasi (Sudarmadji dan Sularto, 2007). Evans, 2003 (dalam Raditya, 2012:23) menyatakan bahwa pengungkapan memiliki arti menyediakan informasi dalam laporan keuangan yang meliputi laporan keuangan itu sendiri, catatan atas laporan keuangan, dan pengungkapan tambahan yang berkaitan dengan laporan keuangan. Pengungkapan terkait dengan bagaimana suatu perusahaan 
dapat menjawab pertanyaan-pertanyaan berikut :

1. Untuk siapa informasi diungkapkan?

2. Mengapa pengungkapan perlu dibuat?

3. Berapa banyak informasi yang harus diungkapkan?

4. Kapan informasi harus diungkapkan?

Keempat pertanyaan tersebut harus mampu dijawab oleh perusahaan yang akan melakukan pengungkapan untuk mengetahui pihak mana saja yang akan melakukan pengungkapan untuk mengetahui pihak mana saja yang akan menggunakan informasi tersebut, tujuan atau alasan dari dilakukannya pengungkapan, jumlah pengungkapan yang dibutuhkan, dan waktu yang tepat untuk melakukan pengungkapan (Raditya, 2012).

Menurut ajaran Islam Allah adalah Tuhan Yang Maha Esa yang telah menciptakan alam dan seluruh isinya, maka dari itu kepemilikan mutlak adalah milik Allah SWT (Permatasari, 2015:56). Manusia di muka bumi hanyalah seorang khalifah yang memiliki tanggung jawab atas dirinya, perbuatannya, dan perlakuannya terhadap semua ciptaan Allah lainnya.

Manusia memiliki kewajiban untuk menaati seluruh perintah Allah dan menjauhi segala larangan Allah. Manusia harus menerapkan perintah Allah yaitu ajaran-ajaran Islam pada seluruh aspek kehidupan, karena manusia akan mempertanggungjawabkan seluruh perbuatannya pada hari kiamat kelak.

Penerapan ajaran Islam ini juga mencakup hingga aspek ekonomi. Dalam ekonomi islam, akuntanbilitas dibutuhkan untuk menghasilkan pengungkapan yang benar, adil, dan transparasi. Dalam aspek ekonomi salah satu hal yang perlu diperhatikan adalah kejujuran yang secara lebih spesifik adalah akuntabilitas.

Haniffa (2002) menyatakan bahwa,

"ISR adalah perpanjangan pelaporan sosial yang tidak hanya meliputi harapan dewan pengurus atas pandangan masyarakat terhadap peran perusahaan dalam ekonomi tetapi juga pemenuhan perspektif spiritual untuk pengguna laporan yang muslim. Praktek pengungkapan tanggung jawab sosial Islam akan berbeda dengan pelaporan sosial konvensional karena prinsip yang mendasari berbeda meskipun konsep dasarnya yaitu tanggung jawab sosial dan akuntabilitas ditunjukkan oleh keduanya."

Pengungkapan tanggung jawab sosial menurut perspektif Islam adalah sebuah usaha untuk memastikan pemangku kepentingan berhati-hati mengenai kesesuaian dan ketidaksesuaian prinsip syariah pada suatu aktivitas bisnis untuk membantu mereka dalam membuat keputusan ekonomi dan keputusan religius untuk mencapai falah (kesuksesan di dunia dan di akhirat).

Haniffa (2002) mengembangkan indeks ISR berdasarkan enam tema yaitu kevangan dan investasi, produk, karyawan, peminjam dana, masyarakat, 
dan lingkungan. Othman dkk (2009)

menambahkan satu tema pada indeks

pengungkapan ISR yang

dikembangkannya yaitu tata kelola

perusahaan. Penelitian ini akan

menggunakan indeks ISR yang dirancang oleh Othman dkk (2009). Berikut adalah enam tema pengungkapan Islamic Social Reporting yang digunakan dalam penelitian ini:

1. Keuangan dan pendanaan, tema ini terdiri dari 6 item yaitu dana riba/bunga/pendapatan non halal, gharar (ketidakjelasan), zakat, kebijakan atas keterlambatan pembayaran piutang nasabah, Current value Balance Sheet, dan Value Added Statement.

2. Produk dan Jasa, item terdiri dari produk ramah lingkungan (Green Product), status kehalalan produk, keamanan dan kualitas produk, dan pelayanan atas keluhan konsumen.

3. Karyawan, item indeks yang terdiri dari jam kerja/hari cuti/remunerasi karyawan, pelatihan dan pendidikan karyawan, kesetaraan gender karyawan, Keterlibatan karyawan dalam diskusi manajemen, kesehatan dan keselamatan karyawan, lingkungan, dll.

4. Masyarakat, item yang terdapat pada tema ini seperti kegiatan amal shadagoh, wakaf, Qardhul Hasan, kegiatan sukarela karyawan, beasiswa pendidikan, dan kegiatan sosial lainnya.

5. Lingkungan hidup, yang terdiri dari informasi mengenai konservasi lingkungan hidup, kegiatan yang tidak menimbulkan polusi, pendidikan mengenai lingkungan hidup, audit lingkungan, dan sistem manajemen lingkungan.

6. Tata Kelola Perusahaan, kepatuhan terhadap syariah, struktur kepemilikan saham, profil dewan direksi, dan kebijakan anti korupsi.
Bukan hanya bank konvensional saja yang dikenal oleh masyarakat, tetapi muncul juga bank syariah yang kini mulai banyak diminati oleh masyarakat. Pengertian bank syariah menurut (Soemitra, 2010:61) suatu lembaga kevangan yang menjalankan kegiatan usahanya berdasarkan prinsip-prinsip syariah dan menurut jenisnya terdiri atas Bank Umum Syariah (BUS), Unit Usaha Syariah (UUS), dan Bank Pembiayaan Rakyat Syariah (BPRS). Bank syariah merupakan bank yang dikenal mengedepankan prinsip profit and loss sharing (bagi untung dan bagi rugi).

Jadi pada bank syariah tidak dikenal adanya bunga, sedangkan pada bank konvensional dikenal selalu membebankan bunga kepada nasabahnya. Menurut Undang-Undang No. 21 Tahun 2008 tentang perbankan syariah. Pengertian bank syariah adalah bank yang menjalankan kegiatan usahanya berdasarkan prinsip-prinsip syariah dan menurut jenisnya terdiri atas Bank Umum Syariah (BUS), Unit Usaha Syariah (UUS), dan Bank Pembiayaan Rakyat Syariah (BPRS).

Hipotesis

$\mathrm{HI}$ : Terdapat perbedaan tingkat pengungkapan ISR antara perbankan syariah di Indonesia dan Malaysia.

Model Analisis

Model analisis dari penelitian ini diawali dengan checklist pada laporan kevangan bank syariah di Indonesia dan Malaysia, melakukan scoring dengan 
memberi angka 1 setiap item yang diungkapkan, kemudian membandingkan hasil scoring antara kedua negara, setelah itu dilanjutkan dengan melakukan uji beda independent sample t-Test/Mann whitney untuk mengetahui membuktikan hipotesis dan mengetahui apakah ada perbedaan ISR pada Bank Umum Syariah di kedua Negara tersebut.

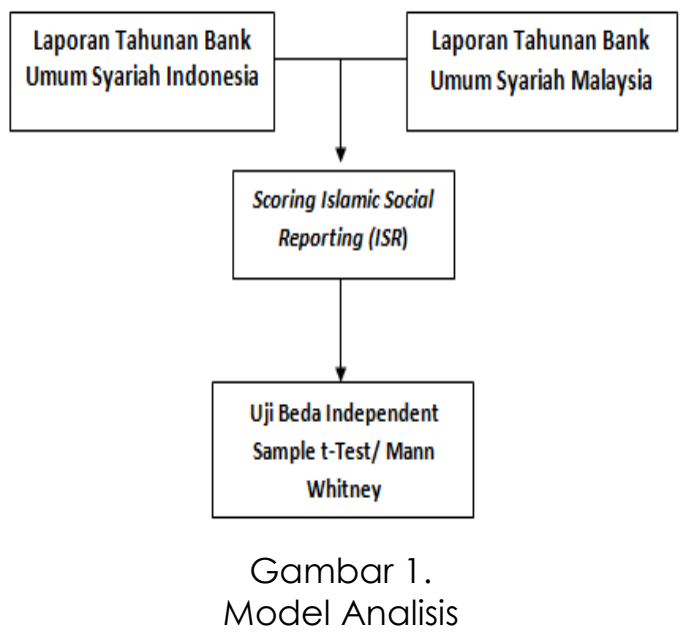

\section{METODOLOGI PENELITIAN}

\section{Pendekatan Penelitian}

Penelitian ini dilakukan dengan menggunakan pendekatan kuantitatif, yaitu penelitian yang menitikberatkan pada pengujian hipotesis, mengukur variabel yang sedang diteliti dan akan menghasilkan kesimpulan yang dapat digeneralisasikan, serta menggunakan alat bantu statistik.

\section{Identifikasi Variabel}

Untuk menjawab rumusan masalah dan menguji hipotesis, maka variabel yang digunakan dalam penelitian ini adalah jumlah indeks ISR yang terdiri dari enam tema. Yaitu keuangan dan pendanaan, produk dan jasa, karyawan, masyarakat, lingkungan hidup, dan tata kelola perusahaan.

\section{Definisi Operasional Variabel}

Untuk memberikan gambaran yang jelas mengenai variabel yang digunakan dalam penelitian ini, maka variabel tersebut dapat didefinisikan sebagai berikut:

a. Islamic Social Reporting (ISR)

Variabel yang digunakan dalam penelitian ini adalah tanggung jawab sosial perbankan syariah yang dilihat melalui tingkat pengungkapan Islamic Social Reporting berdasarkan indeks ISR. Indeks ISR yang akan digunakan dalam penelitian ini menggunakan indeks ISR yang telah dirancang oleh Othman dkk (2009).

Pemberian nilai pada content analysis yang terdiri dari 43 item indeks ISR pada penelitian ini tidak diukur untuk berapa kali jumlah kejadian untuk masing-masing item dalam satu tahun periode pengungkapan, tetapi selama minimal terdapat satu kali pengungkapan ISR, maka item tersebut dianggap telah ada dan diberi nilai (skor) 1. Apabila item tersebut tidak ditemukan dan diungkapkan dalam laporan perusahaan maka item tersebut akan diberi nilai (skor) 0 . Nilai tingkat pengungkapan Islamic Social Reporting tersebut kemudian dihitung dengan rumus (Ahzar dan Trisnawati, 2013):

Tingkat pengungkapan = item yang dipenuhi Skor item maksimum 
Pemberian skor ini tidak menilai kualitas perusahaan melalui item-item pada indeks ISR, tetapi hanya menilai tingkat atau jumlah skor pengungkapan pada indeks ISR. Penilaian item indeks pengungkapan ini akan diidentifikasi dan dikumpulkan dari analisis atau penemuan dari laporan tahunan perusahaan.

\section{Jenis dan Sumber Data}

Data sekunder dalam penelitian ini berupa laporan tahunan bank syariah yang ada di Indonesia dan Malaysia. Laporan tahunan didapatkan dari website masing-masing bank atau untuk laporan tahunan perbankan syariah di Indonesia dapat diperoleh dari situs www.ojk.go.id, sedangkan untuk data laporan tahunan perbankan di Malaysia diperoleh dari situs resmi bank Negara Malaysia yaitu www.bnm.gov.my.

\section{Populasi dan Sampel}

Populasi dalam penelitian ini adalah perbankan syariah yang ada di Indonesia dan Malaysia, yang berjumlah 27 BUS, dan terdiri dari 12 BUS di Indonesia dan 17 BUS di Malaysia.

teknik pengambilan sampel yang digunakan adalah purposive sampling. . Sampel dipilih peneliti dengan sengaja karena ada beberapa pertimbangan tertentu dengan pemilian kriteria sebagai berikut:

1. Bank Syariah di Indonesia dan Malaysia yang berdiri sendiri.

2. Bank syariah tersebut menerbitkan laporan tahunan berturut-turut pada tahun 2012-2014 di kedua negara.

3. Lima bank Syariah terbesar di Indonesia dan Malaysia dilihat dari total asetnya.

\section{Teknis Analisis}

Dalam penelitian ini, berikut langkahlangkah yang diambil untuk melakukan analisis dalam penelitian ini, antara lain:

1. Melakukan cheklist, yaitu dengan memberi nilai 1 jika terdapat satu item yang diungkapkan dalam laporan tahunan, dan nilai 0 jika item tersebut tidak di ungkapkan.

2. Melakukan scoring yakni dengan menghitung nilai tingkat pengungkapan Islamic Social Reporting. Nilai tingkat pengungkapan Islamic Social Reporting tersebut dihitung dengan rumus (Ahzar dan Trisnawati, 2013):

Tingkat pengungkapan= item yang dipenuhi

Skor item maksimum

3. Uji statistik deskriptif, statistik deskriptif memberikan gambaran atau deskripsi suatu data yang dilihat dari nilai ratarata (mean), standar deviasi, varian, maksimum, dan minimum

4. Uji Normalitas, uji ini dilakukan untuk mengetahui apakah data berdistribusi normal atau tidak yang diketahui dengan melakukan uji Normal Kolmogrov-smirnov (Sujarweni, 2014:52). Pengambilan keputusan dari uji ini adalah:

a. Jika sig > 0,05 maka data berdistribusi normal 
b. Jika sig < 0,05 maka data berdistribusi tidak normal.

5. Pengujian hipotesis dilakukan dengan menggunakan independent sample ttest. Akan tetapi, jika pada saat uji normalitas data diketahui tidak berdistribusi normal, maka pengujian hipotesis dilakukan dengan menggunakan uji mann-whitney.

\section{HASIL DAN PEMBAHASAN}

Berdasarkan content analysis yang telah dilakukan, ditemukan bahwa ratarata skor tingkat pengungkapan ISR perbankan syariah di Indonesia selama tahun 2012-2014 lebih tinggi daripada rata-rata skor tingkat pengungkapan ISR perbankan syariah di Malaysia dalam periode yang sama. Jumlah rata-rata pelaksanaan dan pengungkapan tanggung jawab sosial yang dilaksanakan bank syariah selama tiga tahun di Indonesia mencapai $58,61 \%$ dari total 43 item pengungkapan. Sedangkan Malaysia mendapat skor sebesar $47,28 \%$ dari 43 item pengungkapan dan memiliki selisih skor sebesar 10,86\%. Hal tersebut menunjukkan bahwa pelaksanaan tanggung jawab sosial dan pengungkapannya yang dilakukan oleh perbankan syariah Indonesia lebih baik daripada Malaysia. Artinya item-item indeks ISR yang diungkapkan bank syariah di Indonesia lebih banyak daripada itemitem indeks ISR yang diungkapkan oleh bank syariah di Malaysia.

\section{Analisis Statistik Deskriptif}

Berdasarkan tabel 4.1, besarnya nilai rata-rata (mean) perbankan Syariah di Indonesia untuk nilai skor ISR yaitu sebesar 58,1393 . Nilai minimum menunjukkan angka sebesar 41,86 dan nilai maksimum menunjukkan angka sebesar 72,09. Sehingga dapat disimpulkan bahwa perbankan Syariah di Indonesia dalam mengungkapkan ISR berdasarkan indeks ISR, rata-rata mengungkapkan sebanyak 25 item atau jika dipersentasekan adalah sebesar $58,14 \%$.

Tabel 1.

Hasil Analisis Statistik Deskriptif

\begin{tabular}{|l|l|l|r|l|l|}
\hline & N & Mean & $\begin{array}{c}\text { Std. } \\
\text { Deviation }\end{array}$ & Min & Max \\
\hline Indonesia & 15 & 58.1393 & 9.17659 & 41.86 & 72.09 \\
\hline Malaysia & 15 & 47.2853 & 9.77583 & 34.88 & 62.79 \\
\hline $\begin{array}{l}\text { Valid N } \\
\text { (listwise) }\end{array}$ & 15 & & & & \\
\hline
\end{tabular}

Sumber: Data diolah

Sedangkan tingkat pengungkapan terkecil yakni sebanyak 18 item pengungkapan atau $41,86 \%$ dan tingkat pengungkapan skor ISR terbesar adalah 31 item pengungkapan atau sebesar $72,09 \%$.

Sedangkan tingkat pengungkapan ISR perbankan syariah di Malaysia berdasarkan indeks ISR menunjukkan nilai rata-rata (mean) sebesar 47,2853 dengan nilai minimum 34.88 dan nilai maksimum 62,79 . Hal ini menunjukkan bahwa ratarata pengungkapan ISR yang dilakukan oleh perbankan Syariah Malaysia berdasarkan indeks ISR adalah sebanyak 20 item atau sebesar 47,28\%. Nilai minimum menunjukkan tingkat pengungkapan terkecil yang dilakukan 
Widayati, et al/Jurnal Ekonomi Syariah Teori dan Terapan Vol. 4 No. 1 Januari 2017: 62-72; ANALISIS PERBEDAAN KINERJA SOSIAL DENGAN INDEKS ISLAMIC SOCIAL REPORTING (ISR) PADA PERBANKAN SYARIAH YANG ADA DI INDONESIA DAN MALAYSIA

perbankan Syariah di Malaysia yakni sebanyak 15 item pengungkapan atau $34,88 \%$ dan tingkat pengungkapan terbesar adalah 27 item pengungkapan atau sebesar $62,79 \%$.

\section{Uji Normalitas}

Tabel 2.

Uji Normalitas Kolmogorov-Smirnov

\begin{tabular}{|l|l|l|l|l|}
\hline Variabel & Kategori & $\begin{array}{l}\text { Batas } \\
\text { Sig }\end{array}$ & $\begin{array}{l}\text { Nilai } \\
\text { Asymp.sig. }\end{array}$ & Ket \\
\hline \multirow{2}{*}{ ISR } & Indonesia & 0,05 & 0,953 & Normal \\
\cline { 2 - 2 } \cline { 4 - 5 } & Malaysia & & 0,916 & Normal \\
\hline
\end{tabular}

Sumber: Data diolah

Berdasarkan tabel 2. dapat diketahui bahwa data perbankan Syariah di Indonesia serta di Malaysia berdistribusi normal. Hal ini ditunjukkan dengan tingkat signifikansi perbankan Syariah di Indonesia sebesar 0,953, sedangkan tingkat signifikansi perbankan Syariah di Malaysia sebesar 0,916. Kedua tingkat signifikansi dari perbankan Syariah di Indonesia dan Malaysia menunjukkan tingkat signifikansi yang lebih besar dari 0,05 sehingga dapat dikatakan normal, dan memenuhi syarat untuk dilakukan uji Indepndent Sample Ttest.

\section{Uji Hipotesis}

Tabel 3.

Tabel levene's test

\begin{tabular}{|c|c|c|c|}
\hline Variabel & \multicolumn{2}{|l|}{$\begin{array}{l}\text { Levene's test } \\
\text { for equality of } \\
\text { variance }\end{array}$} & Keterangan \\
\hline \multirow{2}{*}{ ISR } & $\mathbf{F}$ & Sig & Homogen \\
\cline { 2 - 3 } & 0.198 & 0.659 & \\
\hline
\end{tabular}

Sumber: Data diolah

Pada kolom Levene test menunjukkan bahwa tingkat signifikansinya sebesar 0,659 . Hal ini menunjukkan bahwa tingkat signifikansi yang diperoleh lebih dari 0,05 $(>0,05)$ sehingga tingkat signifikansi yang dilihat adalah angka pada kolom t-test Equal Variance Assumed.

Nilai t-test Equal Variance Assumed menunjukkan angka 0,004 (Tabel 4.4). Angka tersebut menunjukkan bahwa nilai signifikansi tingkat pengungkapan ISR perbankan syariah di Indonesia dengan perbankan syariah di Malaysia lebih kecil dari 0,05 atau $5 \%$, sehingga hipotesis pada penelitian ini diterima, dan dapat diambil kesimpulan bahwa terdapat perbedaan yang signifikan antara tingkat pengungkapan ISR perbankan syariah di Indonesia dan perbankan syariah di Malaysia.

Tabel 4.

Uji Independent Sample t-test

\begin{tabular}{|c|l|c|c|}
\hline \multicolumn{4}{|c|}{ Independent Sample t-test } \\
\hline \multirow{2}{*}{ ISR } & $\begin{array}{c}\text { Sig. } \\
\text { (2tailed) }\end{array}$ & Keterangan \\
& $\begin{array}{l}\text { Equal } \\
\text { variances } \\
\text { Assumed }\end{array}$ & 0.004 & $\begin{array}{c}\text { H1 diterima } \\
\text { (ada } \\
\text { perbedaan } \\
\text { signifikan) }\end{array}$ \\
\cline { 2 - 3 } & $\begin{array}{l}\text { Equal } \\
\text { variances } \\
\text { not assumed }\end{array}$ & 0.004 & \\
\hline
\end{tabular}

\section{Pembahasan}

Berdasarkan hasil content analysis, ditemukan bahwa secara umum perbankan Syariah di Indonesia memiliki skor tingkat pengungkapan ISR yang lebih tinggi daripada perbankan syariah di 
Malaysia di setiap tahunnya. Hal ini menunjukkan bahwa perbankan syariah di Indonesia melaksanakan tanggung jawab sosialnya dan mengungkapkannya kepada publik secara lebih baik dan lebih terbuka daripada perbankan syariah di Malaysia.

Hasil content analysis ini berbeda dengan hasil dari penelitian Sofyani (2012) yang menyatakan bahwa tingkat kinerja sosial perbankan syariah di Malaysia yang dilihat dari skor tingkat pengungkapan ISR lebih baik daripada tingkat kinerja sosial perbankan syariah di Indonesia. Perbedaan tersebut terjadi karena jumlah sampel bank syariah, periode, serta itemitem pengungkapan yang digunakan dalam penelitian ini berbeda, sehingga hasil content analysis pada penelitian ini berbeda dan tidak mendukung hasil penelitian sebelumnya.

3 tema yang membuat nilai skor ISR perbankan Syariah di Malaysia lebih rendah dibandingkan dengan perbankan di Indonesia, yaitu:

1. Tema keuangan dan Pendanaan, perbankan Syariah di Indonesia memiliki skor ISR yang lebih tinggi dari perbankan Syariah di Malaysia pada tema ini, yaitu karena pada item kebijakan atas keterlambatan piutang, perbankan Syariah di Malaysia sama sekali tidak mengungkapkan tentang kebijakan tersebut.

2. Tema Masyarakat, pada tema ini nilai skor ISR antar item relatif berbeda di setiap item baik itu pada perbankan Syariah maupun Malaysia setiap tahunnya. Dikarenakan program-program sosial yang dilaksanakan oleh bank Syariah di setiap tahunnya berbeda.

3. Tema Lingkungan Hidup, pada tema ini rata-rata item yang diungkapkan oleh perbankan Syariah di Indonesia dan Malaysia adalah konservasi lingkungan hidup, kegiatan yang tidak membuat polusi lingkungan hidup (pengelolaan limbah, penguraian emisis, dIII), dan pendidikan. Untuk tema sistem manajemen lingkungan, perbankan syariah hanya mengungkapkan $20 \%$. Pada tema ini bank Syaiah di Indonesia memiliki total skor 27 sedangkan Malaysia 15

Nilai t-test Equal Variance Not Assumed menunjukkan angka 0,003. Angka tersebut menunjukkan bahwa nilai signifikansi tingkat pengungkapan ISR perbankan syariah di Indonesia dengan perbankan syariah di Malaysia lebih kecil dari 0,05 atau 5\%, sehingga hipotesis pada penelitian ini diterima ( $\mathrm{H} 1$ diterima), yaitu adanya perbedaan signifikan pada pengungkapan indeks Islamic Social Reporting pada perbankan syariah yang ada di Indonesia dan Malaysia.

adanya perbedaan nilai skor Islamic Social Reporting (ISR) pada bank Syariah di Indonesia dan Malaysia tersebut dikarenakan:

1. Belum adanya peraturan tetap yang mengatur mengenai pengungkapan 
indeks ISR pada laporan tahunan perbankan Syariah.

2. Item ISR perlu di eksplisitkan maknanya atau tertulis dengan jelas, karena item-item yang maknanya kurang tertulis dengan jelas menyebabkan tingkat pengungkapan yang dilakukan masing-masing bank syariah di Indonesia dan Malaysia belum terlaksana atau ditemukan secara sempurna (100\%).

3. Perbedaan tingkat pengungkapan yang dilakukan oleh perbankan Syariah di Indonesia dan Malaysia dapat disebabkan oleh faktor internal

4. Perusahaan yang berukuran besar mengungkapkan informasi yang lebih banyak karena ukuran perusahaan yang besar berarti tanggung jawab yang besar pula terhadap kesejahteraan para pemangku kepentingan dan lingkungan, dan membutuhkan pengungkapan yang lebih lengkap dan luas. Selain itu perusahaan yang lebih besar memiliki lebih banyak sumber daya keuangan, fasilitas, dan sumber daya manusia untuk mengungkapkan lebih banyak Islamic Social Reporting, mereka akan mengungkapkan lebih banyak informasi meskipun dengan tidak adanya standar atau petunjuk yang bisa diikuti. Kesimpulan ini mendukung penelitian sebelumnya, yaitu penelitian Othman dkk (2009:15) dan Permatasari (2015:77).

\section{DAFTAR PUSTAKA}

AAOIFI. (2010). Accounting, Auditing \& Governance Standards for Islamic Financial Institutions. AAOIFI: Manama.

Ahzar, F.A., Trisnawati R. 2013. Pengungkapan Islamic Social Reporting pada Bank Syariah di Indonesia. Surakarta: Universitas Muammadiyah Surakarta.

Bank Negara Malaysia. List of Licensed Banking Institutions in Malaysia. (Online).(www.bnm.gov.my/index.php? $c h=l i \& c a t=i i b \&$ type $=\| B \&$ fund $=0 \& c u=0$, diakses 12 Januari 2016).

Evans, T. G. (2003). Accounting Theory: Contemporary Accounting Issues. United States of America: Thomson

Global Islamic Financial Reporting. Islamic Finance Country Index 2014. (Online). (http://www.gifr.net/gifr_2014.htm, diakses 25 Februari 2016)

Global Reporting Intiative. 2013. Pedoman Pelaporan Keberlanjutan. Amsterdam: Global Reporting Initiative.

Haniffa, R. 2002. Social Reporting Disclosure-An Islam Prespektif. Indonesian Management \& Accounting Research Vol.1 No. 2 pp. 128-146

Hasan dan Harahap. 2010. Exploring Corporate Social Responsibility Disclosure: The Case of Islamic Banks. International Journal of Islamic and Middle Eastern Finance and Management Vol 3. No. 3 pp 203-227

Othman dan Thani. 2010. Islamic Social Reporting of Listed Companies in Malaysia. The International Business and Economics Research Journal Vol. 9 No. 4 pp. 135

Othman dkk. 2009. Determinant of Islamic Social Reporting Amoung Top ShariahApproved Companies in Bursa Malaysia. Journal of International Studies-Issue 12. 

ADA DI INDONESIA DAN MALAYSIA

Permatasari, Vina Septiana. 2015. Pengaruh Ukuran Perusahaan, Profitabilitas, dan Ukuran Dewan Direksi Terhadap Indeks Islamic Social Reporting Pada Perusahaan yang Terdaftar dalam Jakarta Islamic Index Tahun 2011-2013. Skripsi tidak diterbitkan. Surabaya Fakultas Ekonomi dan Bisnis Universitas Airlangga.

Raditya, AN. 2012. Analisis Faktor-Faktor yang Mempengaruhi Tingkat Pengungkapan Islamic Social Reporting (ISR) pada Perusahaan yang Masuk Datar Efek Syariah (DES). Skripsi. Depok Fakultas Ekonomi Universitas Indonesia.

Soemitra, Andri. 2010. Bank dan Lembaga Kevangan Syariah. Jakarta: Penerbit Kencana Prenada Media Group.

Sofyani, Ulum, Syam, dan Wahjuni. 2012. Islamic Social Reporting Index Sebagai Model Pengukuran Kinerja Sosial Perbankan Syariah (Studi Komparasi Indonesia dan Malaysia). Malang: Universitas Muhammadiyah Malang.

Sudarmadji, A. M., \& Sularto, L. (2007). Pengaruh Ukuran Perusahaan, Profitabilitas, Leverage, dan Tipe Kepemilikan Perusahaan terhadap Luas Voluntary Disclosure Laporan Keuangan Tahunan. Proceeding PESAT (Psikologi, Ekonomi, Sastra, Arsitek, \& Sipil). Depok.

Sugiyono. 2012. Metode Penelitian Kuantitatif, Kualitatif, dan R\&D. Cetakan ke- 17. Bandung: CV Alfabeta.

Sujarweni, V Wiratna. 2014. SPSS Untuk Penelitian. Yogyakarta: Penerbit: Pustaka baru press.

www.bi.go.id, diakses pada tanggal 12 Januari 2016.

www.ojk.go.id, diakses pada tanggal 16 Januari 2016. 